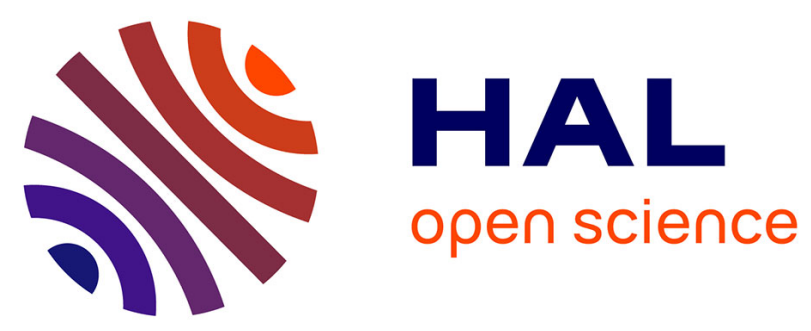

\title{
Surface characterization of poly-2-vinylpyridine-A polymer for area selective deposition techniques
}

Matthew Snelgrove, Clara Zehe, Ross Lundy, Pravind Yadav, Jean-Pascal

Rueff, Robert O'Connor, Justin Bogan, Greg Hughes, Enda Mcglynn, Michael Morris, et al.

\section{To cite this version:}

Matthew Snelgrove, Clara Zehe, Ross Lundy, Pravind Yadav, Jean-Pascal Rueff, et al.. Surface characterization of poly-2-vinylpyridine-A polymer for area selective deposition techniques. Journal of Vacuum Science \& Technology A, 2019, 37, pp.050601. hal-02303298

\section{HAL Id: hal-02303298 \\ https://hal.sorbonne-universite.fr/hal-02303298}

Submitted on 2 Oct 2019

HAL is a multi-disciplinary open access archive for the deposit and dissemination of scientific research documents, whether they are published or not. The documents may come from teaching and research institutions in France or abroad, or from public or private research centers.
L'archive ouverte pluridisciplinaire HAL, est destinée au dépôt et à la diffusion de documents scientifiques de niveau recherche, publiés ou non, émanant des établissements d'enseignement et de recherche français ou étrangers, des laboratoires publics ou privés. 


\section{Surface characterization of poly-2-vinylpyridine-A polymer for area selective deposition techniques}

Matthew Snelgrove, Clara Zehe, Ross Lundy, Pravind Yadav, Jean-Pascal Rueff, Robert O'Connor, Justin Bogan, Greg Hughes, Enda McGlynn, Michael Morris, and Pierre Giovanni Mani-Gonzalez

Citation: Journal of Vacuum Science \& Technology A 37, 050601 (2019); doi: 10.1116/1.5115769

View online: https://doi.org/10.1116/1.5115769

View Table of Contents: https://avs.scitation.org/toc/jva/37/5

Published by the American Vacuum Society

\section{ARTICLES YOU MAY BE INTERESTED IN}

Area-selective atomic layer deposition of cobalt oxide to generate patterned cobalt films

Journal of Vacuum Science \& Technology A 37, 020905 (2019); https://doi.org/10.1116/1.5066437

Transition in layer structure of atomic/molecular layer deposited $\mathrm{ZnO}$-zincone multilayers Journal of Vacuum Science \& Technology A 37, 040602 (2019); https://doi.org/10.1116/1.5105348

Review Article: Spectroscopic microreactors for heterogeneous catalysis Journal of Vacuum Science \& Technology A 37, 050801 (2019); https://doi.org/10.1116/1.5108901

Surface prefunctionalization of $\mathrm{SiO}_{2}$ to modify the etch per cycle during plasma-assisted atomic layer etching Journal of Vacuum Science \& Technology A 37, 051003 (2019); https://doi.org/10.1116/1.5110907

Functional model for analysis of ALD nucleation and quantification of area-selective deposition Journal of Vacuum Science \& Technology A 37, 020911 (2019); https://doi.org/10.1116/1.5054285

Overview of atomic layer etching in the semiconductor industry Journal of Vacuum Science \& Technology A 33, 020802 (2015); https://doi.org/10.1116/1.4913379

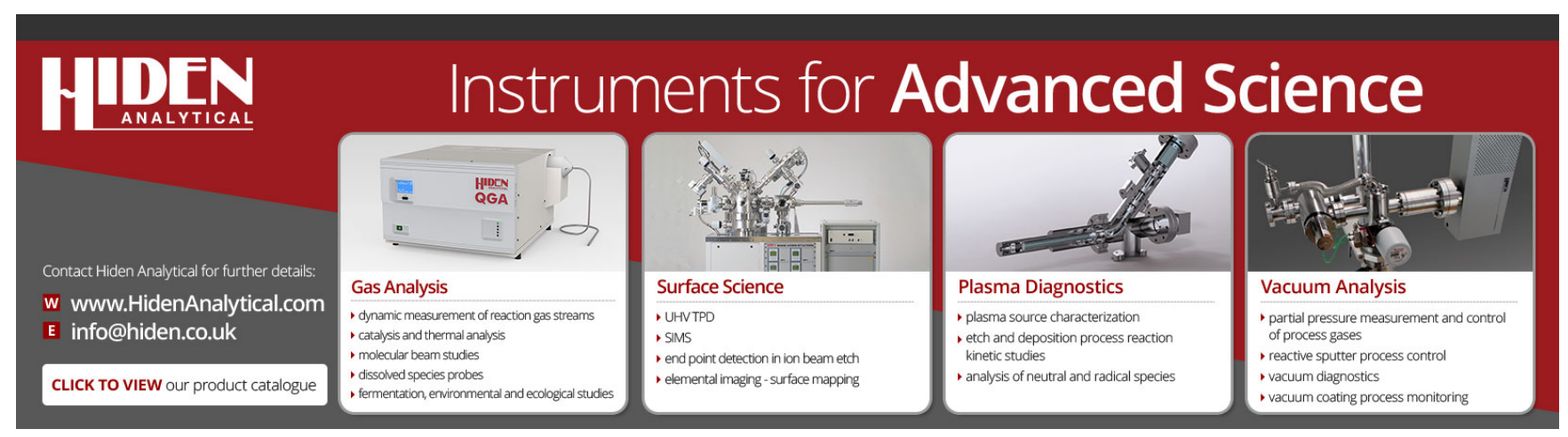




\title{
Letters
}

\section{Surface characterization of poly-2-vinylpyridine-A polymer for area selective deposition techniques}

\author{
Matthew Snelgrove, ${ }^{1}$ Clara Zehe, ${ }^{1}$ Ross Lundy, ${ }^{2}$ Pravind Yadav, ${ }^{2}$ Jean-Pascal Rueff, ${ }^{3,4}$ \\ Robert O'Connor, ${ }^{1}$ Justin Bogan, ${ }^{1}$ Greg Hughes, ${ }^{1,5}$ Enda McGlynn, ${ }^{1,5}$ Michael Morris, ${ }^{2}$ \\ and Pierre Giovanni Mani-Gonzalez ${ }^{6}$ \\ ${ }^{1}$ School of Physical Sciences, Dublin City University, Glasnevin, Dublin 9, Ireland \\ ${ }^{2} A M B E R$, Trinity College Dublin, College Green, Dublin 2, Ireland \\ ${ }^{3}$ Synchrotron SOLEIL L'Orme des Merisiers, BP 48 Saint-Aubin, 91192 Gif-sur-Yvette, France \\ ${ }^{4}$ CNRS, Laboratoire de Chimie Physique - Matiére et Rayonnement (LCPMR), Sorbonne Université, \\ F-75005 Paris, France \\ ${ }^{5}$ National Centre for Plasma Science and Technology, Dublin City University, Glasnevin, Dublin 9, Ireland \\ ${ }^{6}$ Instituto de Ingeniería y Tecnología, Departamento de Física y Matemáticas, Universidad Autónoma de \\ Ciudad Juárez, Ave. Del Charro 450, Cd. Juárez C.P., 32310 Chihuahua, Mexico
}

(Received 19 June 2019; accepted 16 July 2019; published 2 August 2019)

\begin{abstract}
Thin films of $\mathrm{OH}$ terminated poly-2-vinylpyridine (P2VP), a polymer with potential for infiltration mediated thin film deposition, area selective deposition (ASD), and small feature size development via block copolymer (BCP) self-assembly, have been studied with hard x-ray photoelectron spectroscopy. From the N $1 s$ and $\mathrm{C} 1 s$ core level spectra, accurate values for the binding energy positions of the species present in the films were obtained, providing clear evidence for signals associated with pyridine bonds. The aromatic ring on the P2VP side chain is clearly identified in the studied core levels. These observations allow for a complete understanding of the chemical environment of the polymer and provide evidence of the potential reactions that can occur with metal diffusion into P2VP. Transmission electron microscopy, attenuated total reflection infrared spectroscopy, and atomic force microscopy measurements reveal high quality films, and this work provides a reference base for this functional material in terms of its utility for ASD, $\mathrm{BCP}$, and subsequent atomic layer deposition based polymer infiltration processes. Published by the AVS. https://doi.org/10.1116/1.5115769
\end{abstract}

\section{INTRODUCTION}

The limitations of traditional optical lithographic patterning is a well documented concern in the semiconductor industry. ${ }^{1}$ The study of polymers as potential materials for use in area selective deposition (ASD) has become a major field of research for developing alternative nanoelectronic fabrication methods via the acceptance and blocking of infiltrating metals in a variety of different polymer types. ${ }^{2,3}$ This range includes polymers such as polystyrene (PS), poly(methyl methacrylate), poly(ethyleneoxide), and poly(vinylpyridine).$^{4-8}$

Poly-2-vinylpyridine (P2VP) is a leading material in ASD and block copolymer $(\mathrm{BCP})$ research, being a $\mathrm{pH}$-responsive component, ${ }^{9,10}$ while also demonstrating effective segregation when used in a block copolymer architecture with materials such as PS and polyisoprene, ${ }^{11}$ a crucial aspect of BCP morphology. ${ }^{12}$ P2VP has had promising experimental results, being reported to facilitate the fabrication of small and uniform features such as gold nanoparticles. ${ }^{13}$ PS-b-P2VP has been used to create small-device-like structures as reported by Morris and others. ${ }^{14,15}$ The presence of an unshared electron pair on the nitrogen atom of the pyridine ring can facilitate coordination bonding with various species such as metalligand complexes. ${ }^{16-18}$ These factors make P2VP an ideal starting material for infiltration processes, such as atomic layer deposition (ALD), that yield key device elements such as metallic contacts and high-k dielectrics.

Although reported in ASD studies, in-depth photoemission analysis of P2VP films and other common BCP-relevant polymers is limited. The use of polymers for the fabrication of thin films highlights the need for more intricate studies of their surface properties to allow for a better understanding of the material chemistry of complex, chemistry rich, processes, such as ALD. ${ }^{19}$ Sequential infiltration synthesis ALD has been reported in the literature as a particularly successful method of infiltration for a range of polymers. ${ }^{20-22}$

The present work focuses on a hard energy x-ray photoelectron spectroscopy (HAXPES) and subsequent angle resolved HAXPES (ARHAXPES) study of the polymer $\mathrm{P} 2 \mathrm{VP}$. The synchrotron radiation provides high resolution photoemission spectra, allowing for accurate determination of the chemistry of the polymer, while the ARHAXPES method characterizes the thickness and depth-resolved composition of the polymer. ${ }^{23,24}$

The nitrogen atom in the pyridine ring of P2VP (see schematic in Fig. 1) has a localized lone pair of electrons that can interact with other atoms via sigma and pi-pi* interactions. ${ }^{25}$ 

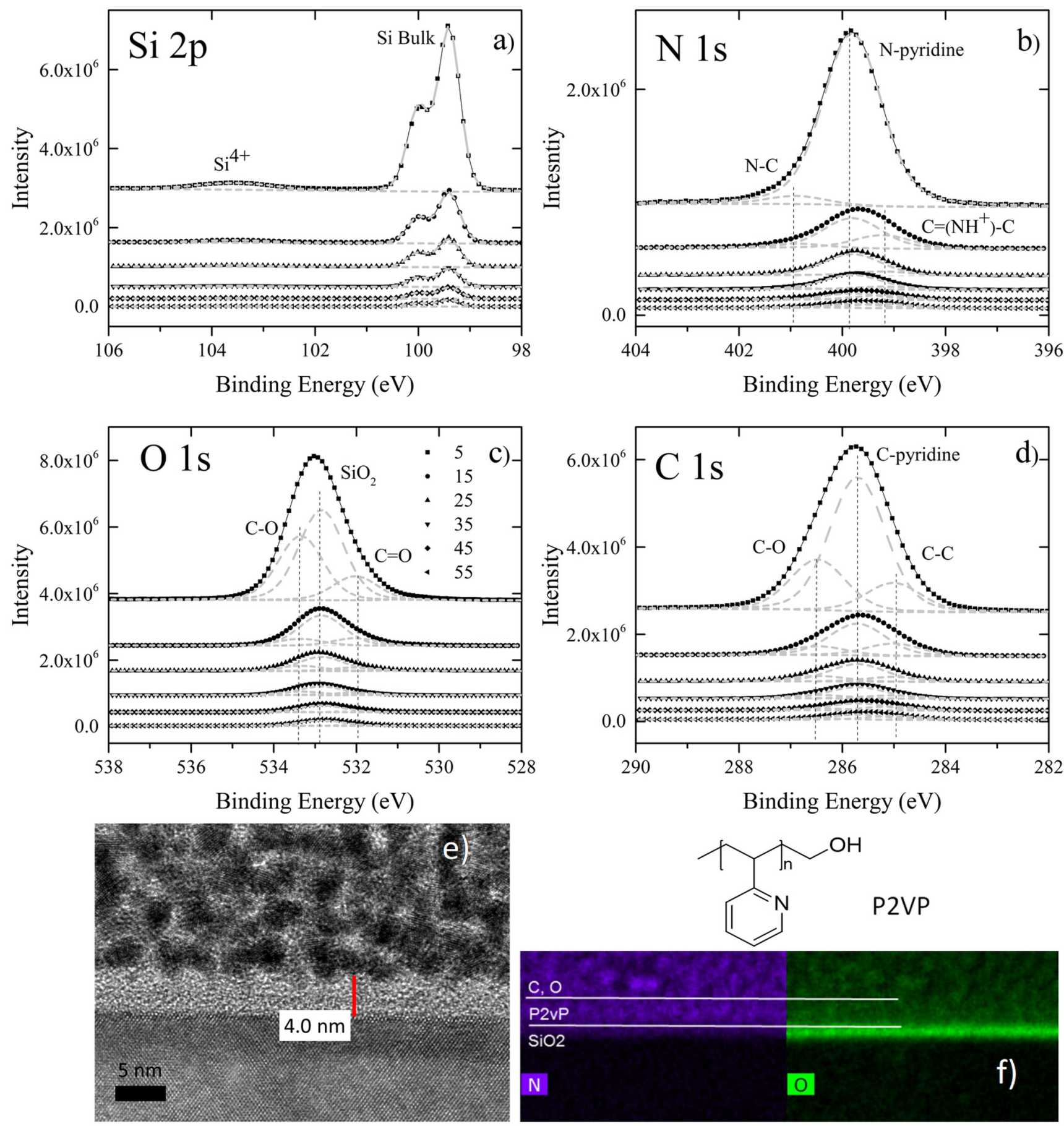

Fig. 1. (a) Si $2 p$, (b) $\mathrm{N} 1 s$, (c) O $1 s$, and (d) $\mathrm{C} 1 s$ core level AR HAXPES spectra of a C/P2VP/SiO $2 / S i$ sample. (e) TEM cross-sectional image of P2VP film. (f) EDX mapping by TEM of P2VP film for $\mathrm{N}$ and $\mathrm{O}$ signals.

In the case of N-pyridine-metal complexes, the electron lone pair on the nitrogen is involved in the bonding interaction. Our previous work presented evidence for $\mathrm{Cu}$ metal ion infiltration and coordination with pyridine via liquid phase salt solution processing. ${ }^{26}$ The role of the electron lone pair is of critical importance in facilitating the coordination bond formation with the infiltrating metal, and this is not thoroughly explored in photoemission reports to date. ${ }^{27}$ In this letter, we report HAXPES measurements including the ARHAXPES dependence of the $\mathrm{C} 1 s$ and $\mathrm{N} 1 s$ signals originating from the P2VP film.

\section{EXPERIMENT}

P2VP films of 0.2 wt.\% were prepared by dissolving $\mathrm{OH}$ terminated poly-2-vinylpyridine ( $\mathrm{P} 2 \mathrm{VP}-\mathrm{OH})$ polymer in tetrahydrofuran and subsequently spin coating at $3000 \mathrm{rpm}$ for $30 \mathrm{~s}$ onto Si substrates following the process used in Ref. 28. $\mathrm{P} 2 \mathrm{VP}-\mathrm{OH}$ is a hydroxyl chain terminated polymer brushlike system that can be coordinated to a silicon oxide surface through a condensation process. ${ }^{29,30}$

HAXPES measurements were undertaken at SOLEIL Synchrotron at the GALAXIES beamline. Spectra were 
acquired at pressures of $1 \times 10^{-9}$ mbar with photon beam energies of $3 \mathrm{keV}$. A Si(111) monochromator was used for the $3 \mathrm{keV}$ beam. The angles chosen for ARHAXPES were in the range of $85^{\circ}-25^{\circ}$, in intervals of $10^{\circ}$ (with normal emission being $90^{\circ}$ ). The sample position at every angle was calibrated to ensure that the photoelectron counts were at their maximum value. The fitting of the photoemission data was performed by AAnalyzer ${ }^{\circledR}$, a program that allows for the simultaneous peak fitting of data acquired at all takeoff angles. ${ }^{31}$ For all of our studies, the use of simultaneous methods is of high importance. ${ }^{32}$ Calculations of the thickness and chemical composition of each layer were obtained using the multilayer method (MLM). ${ }^{33-35}$

High resolution transmission electron microscopy (TEM) experiments to obtain the thickness of the $\mathrm{P} 2 \mathrm{VP}-\mathrm{OH}$ layer were performed on an FEI OSIRIS TEM, with sample preparation performed in an FEI Helios Nanolab $450 \mathrm{~S}$. The sample was capped with $\mathrm{Pt}$ via a gas injection system.

Grazing-angle attenuated total reflection infrared (ATR IR) spectroscopy was performed using a Harrick VariGATR accessory on a Nicolet iS50 spectrometer (unpolarized, angle of incidence is $65^{\circ}, 32$ scans, resolution $8 \mathrm{~cm}^{-1}$ ). Atomic force microscopy (AFM) was used to analyze the P2VP-OH surface roughness on a Bruker Dimension 3100 AFM.

\section{RESULTS}

The measured ARHAXPES spectra of the P2VP-OH film are shown in Fig. 1, with all spectra being shifted so that the $\mathrm{Si}^{0}$ peak on the Si $2 p$ signal [Fig. 1(a)] occurs at $99.4 \mathrm{eV}$ binding energy. ${ }^{35} \mathrm{Si}^{4+}$ was observed at $103.4 \mathrm{eV}$. Figure $1(\mathrm{~b})$ shows the $\mathrm{N} 1 s$ fit, where $\mathrm{C}-\mathrm{N}=\mathrm{C}$ bonds (N-Pyridine) are the main components of the peak, occurring at $399.8 \mathrm{eV}$, while $\mathrm{N}-\mathrm{C}$ at $400.9 \mathrm{eV}$ was also included in the fit. ${ }^{36,37}$ Another signal at $399.2 \mathrm{eV}$ was associated with pyridinehydrogen interaction $\left(\mathrm{C}=\mathrm{NH}^{+}-\mathrm{C}\right.$ bonds). Similar binding energy components in the $\mathrm{N} 1 s$ signal have been reported in the literature but have so far remained uncategorized. ${ }^{38,39}$

The O $1 s$ signal was fitted with four signals [Fig. 1(c)]. The most prominent signal at $532.8 \mathrm{eV}$ is associated with silicon oxide, which is located at the interface between P2VP-OH and the silicon wafer. The other three signals were associated with oxygen in polymer chain bonds, residual oxygen, and adsorbed surface oxygen at 530.6, 532, and $533.3 \mathrm{eV}$, respectively.

The C $1 s$ signal in Fig. 1(d) was fitted with five signals, one of them at $285 \mathrm{eV}$ being associated with $\mathrm{C}-\mathrm{C}$ bonds within the polymer chain as reported by Briggs et al. ${ }^{40}$ The signal with the highest intensity, observed at $285.7 \mathrm{eV}$ is characteristic of pyridinic carbon. ${ }^{41,42}$ The $\mathrm{C}-\mathrm{O}$ signal at $286.5 \mathrm{eV}$ was associated with oxygen bonding to the polymer chain and suboxides at the interfaces. The signals for $\mathrm{C}=\mathrm{O}$ and $\mathrm{O}-\mathrm{C}=\mathrm{O}$ at 287.6 and $288.7 \mathrm{eV}$ were attributed to surface and residual oxygen. ${ }^{43,44}$ The peak fitting parameters for the signals associated with P2VP-OH are displayed in Table I.

By using AR HAXPES, the thicknesses of the different layers present in the sample were obtained. For each core level signal (N $1 s, \mathrm{Si} 2 p, \mathrm{C} 1 s, \mathrm{O} 1 s)$, the attenuation length
TABLE I. Binding energy and peak fit parameters for the P2VP film.

\begin{tabular}{|c|c|c|c|c|c|}
\hline $\begin{array}{l}\text { Core level } \\
\text { peak }\end{array}$ & $\begin{array}{l}h v \\
(\mathrm{ev})\end{array}$ & $\begin{array}{l}\text { Gaussian } \\
(\mathrm{eV})\end{array}$ & $\begin{array}{l}\text { Lorentzian } \\
(\mathrm{eV})\end{array}$ & $\begin{array}{c}\text { Chemical } \\
\text { environment }\end{array}$ & $\begin{array}{c}\text { Binding energy } \\
(\mathrm{eV})\end{array}$ \\
\hline \multirow[t]{2}{*}{$\mathrm{C} 1 s$} & 3000 & 1.11 & 0.27 & $\mathrm{C}-\mathrm{C}$ & 285.0 \\
\hline & & & & C-Pyridine & 285.7 \\
\hline \multirow[t]{2}{*}{$\mathrm{N} 1 s$} & 3000 & 1.13 & 0.51 & $\mathrm{C}=\mathrm{NH}^{+}-\mathrm{C}$ & 399.2 \\
\hline & & & & N-Pyridine & 399.8 \\
\hline
\end{tabular}

of electrons, cross section, areal density, and lattice constant were considered. The assumed composition of the material for theoretical modeling was a layered $\mathrm{C} / \mathrm{P} 2 \mathrm{VP} / \mathrm{SiO}_{2} / \mathrm{Si}$ structure. The thickness calculations were performed using the MLM with the XPS intensity of each species that depends on the takeoff angle. ${ }^{45}$ The bandgap and density of P2VP-OH used for the calculations was $2.25 \mathrm{eV}$ and $1.257 \mathrm{~g} / \mathrm{cm}^{3}$, respectively, in accordance with the literature. ${ }^{46,47}$

The ARHAXPES results are shown in Fig. 2. P2VP and $\mathrm{SiO}_{2}$ dependences were obtained with the C-Pyridine and $\mathrm{Si}^{4+}$ signals, respectively. The uncertainty of the experimental data represents the variation in signal intensity across individual scans. The proposed structure of the analyzed material is presented in the inset of Fig. 2(a), featuring a $\mathrm{C}$ layer above the P2VP-OH film, which itself is above an $\mathrm{SiO}_{2}$ layer
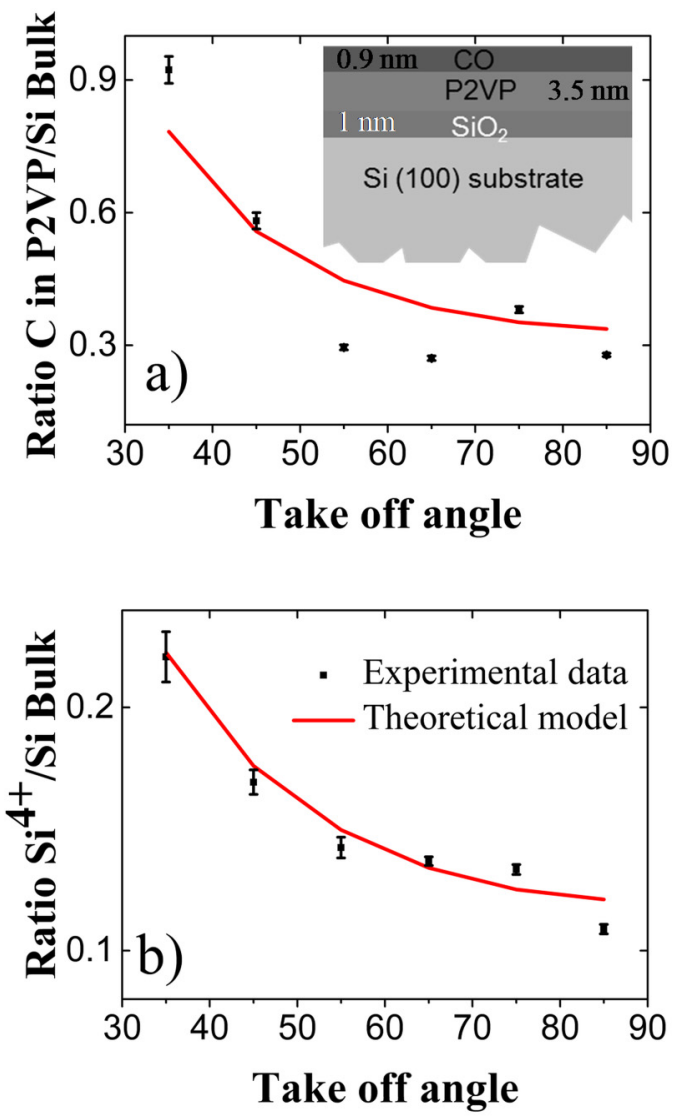

FIG. 2. Angle resolved HAXPES dependence: (a) carbon in P2VP layer and (b) $\mathrm{Si}^{4+}$ in silicon oxide layers. The thickness and chemical composition calculation of each chemical species were considered in the sample. 
on top of the Si bulk. The intensity of the signals associated with the films was divided by the silicon bulk intensity. This was then plotted against the takeoff angle. Comparing the raw data with the theoretical model (MLM), stoichiometry and thickness of the thin layers were obtained.

The thicknesses determined were $1.00 \pm 0.03,3.54 \pm 0.06$, and $0.92 \pm 0.01 \mathrm{~nm}$ for silicon oxide, P2VP, and adventitious carbon layers, respectively. The error was determined by considering two scenarios: when the intensity ratio of the films over the bulk was at maximum and when it was at minimum. TEM images were correlated to photoemission results as shown in Fig. 1(e), showing a thin film of around $4 \mathrm{~nm}$ on top of a silicon dioxide layer. Energy-dispersive $\mathrm{X}$-ray spectroscopy (EDX) mapping by TEM provides evidence that nitrogen is present in this $\mathrm{P} 2 \mathrm{VP}$ region [see Fig. 1(f)]. The stoichiometry of the layers was consistent for each layer according to the chemical composition.

Grazing-angle ATR IR spectroscopy allowed the acquisition of IR spectra even from the ultrathin P2VP-OH film used in this work, after subtracting the silicon background signal. The resulting spectrum is shown in Fig. 3(a). The bands at 2927 and $2854 \mathrm{~cm}^{-1}$ correspond to the vibrational mode of the aliphatic polymer backbone. Deformations in the free backbone lead to the signals at 1473 and $1436 \mathrm{~cm}^{-1}$. The stretching modes of the pyridine ring are located at 1592 and $1570 \mathrm{~cm}^{-1}$ with an additional ring deformation band at $987 \mathrm{~cm}^{-1} .48$ The feature at $787 \mathrm{~cm}^{-1}$ corresponds to out-of-plane
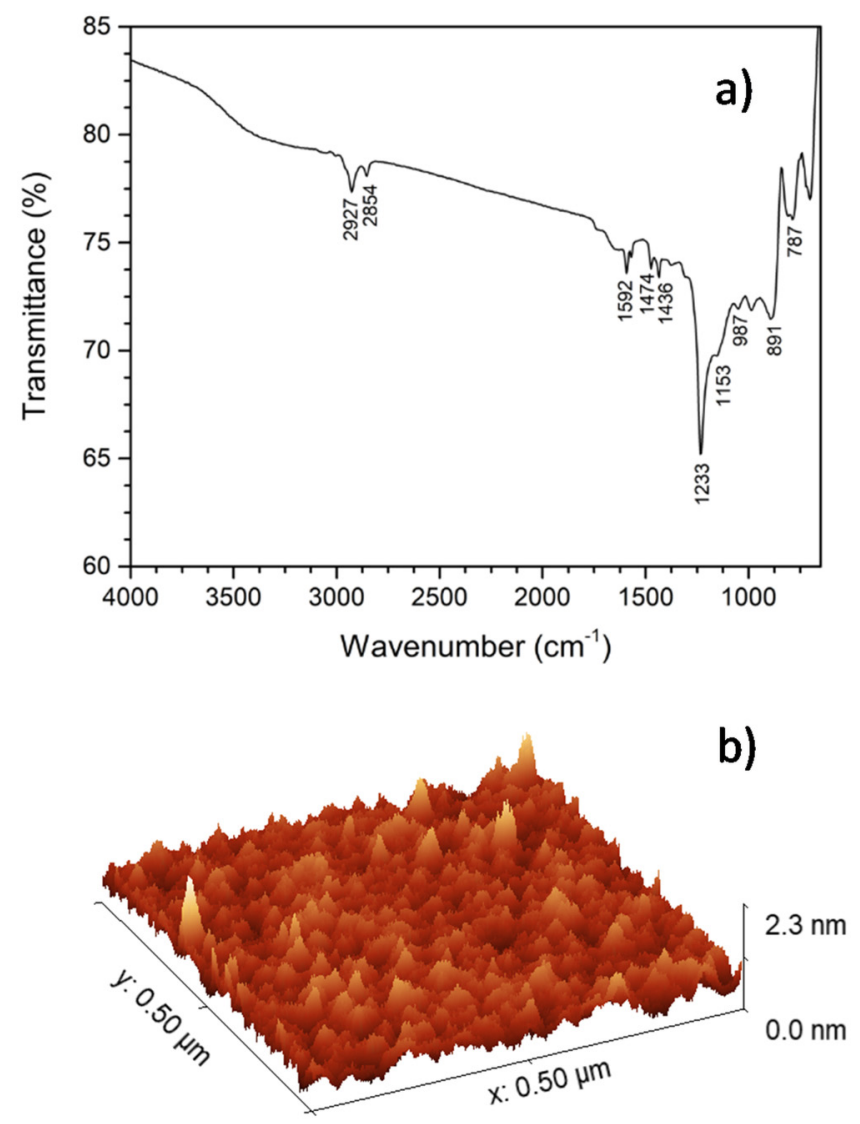

FIG. 3. (a) Grazing-angle ATR IR spectrum of a thin P2VP film. (b) AFM $3 \mathrm{D}$ height image of P2VP surface. deformations of the hydrogen atoms of the pyridine ring. It is shifted to slightly higher frequencies compared to 1,2-substituted aromatic rings due to the higher electronegativity of the nitrogen atom. The signals at 1233 and $1153 \mathrm{~cm}^{-1}$ correspond to $\mathrm{C}-\mathrm{O}-\mathrm{C}$ and $\mathrm{C}-\mathrm{OH}$ vibrations, respectively, resulting from the terminating hydroxy groups of the polymer. These data indicate that partial condensation of the hydroxy group with the hydroxy functionalized silicon substrate may occur during film deposition. This hypothesis agrees with the observation of a visible band at $891 \mathrm{~cm}^{-1}$ corresponding to a $\mathrm{Si}-\mathrm{C}$ bond vibration. ${ }^{49}$

AFM measurements were also performed on the analyzed P2VP-OH samples to assess the physical surface profile of the spun-on polymer film [Fig. 3(b)]. The average root-mean-square surface roughness of the $\mathrm{P} 2 \mathrm{VP}-\mathrm{OH}$ according to AFM analysis was approximately $0.21 \mathrm{~nm}$, which indicates the presence of a very smooth film and is similar to values obtained for the Si substrate.

\section{CONCLUSION}

In summary, we have investigated $\mathrm{P} 2 \mathrm{VP}-\mathrm{OH}$ with a $3 \mathrm{keV}$ HAXPES photon beam, resulting in a nondestructive and high resolution chemical analysis of the film. The P2VP-OH signals were deconvoluted in a robust and highly detailed process. The ARHAXPES analysis of the polymer indicates that pyridine $\mathrm{N}$ will facilitate metal incorporation into the film, with $\mathrm{N} 1 s$ showing a signal corresponding to $\mathrm{H}$ reaction with the N-pyridine lone pair, which has not yet been reported, to the best of our knowledge. Our results suggest that a change in the binding energy corresponds with the lone pair interactions. ARHAXPES and TEM confirm the presence of a uniform thin film of the polymer. The IR spectroscopy indicates the condensation incorporation of the P2VP-OH into the substrate. The work in this letter should act as a reference for future work on this polymer in ASD and BCP infiltration studies.

\section{ACKNOWLEDGMENTS}

This work was supported by the CONACyT fund (No. 2018-000007-01EXTV-00235). The synchrotron measurements were performed at the GALAXIES beamline with approval from SOLEIL (Proposal No. 20180106). The authors also appreciate the technical support from Matt Shaw, Jennifer Mckenna Alan Bell, Christopher O'Neill, and David Bird at Intel Ireland, Leixlip. Helpful advice and GA-ATR IR measurements by Mark Croke and David James from Thermo Fisher Scientific are gratefully acknowledged. This publication has emanated from research conducted with the financial support of Science Foundation Ireland (SFI) under Grant Nos. 12/RC/2278 and 16/SP/3809.

\footnotetext{
${ }^{1}$ R. A. Segalman, Mat. Sci. Eng. R. 48, 191 (2005).

${ }^{2}$ X. Jiang and S. F. Bent, J. Electrochem. Soc. 154, D648 (2007).

${ }^{3}$ R. Chen, H. Kim, P. C. McIntyre, and S. F. Bent, Appl. Phys. Lett. 84, 4017 (2004).
} 
${ }^{4}$ R. Lundy, S. P. Flynn, C. Cummins, S. M. Kelleher, M. N. Collins, E. Dalton, S. Daniels, M. A. Morris, and R. Enright, Phys. Chem. Chem. Phys. 19, 2805 (2017).

${ }^{5}$ Q. Peng, Y.-C. Tseng, S. B. Darling, and J. W. Elam, Adv. Mater. 22, 5129 (2010).

${ }^{6}$ D. Borah et al., J. Phys. D Appl. Phys. 44, 174012 (2011).

${ }^{7}$ J. Varghese, T. Ghoshal, N. Deepak, C. O'Regan, R. W. Whatmore, M. A. Morris, and J. D. Holmes, Chem. Mater. 25, 1458 (2013).

${ }^{8}$ S. Malynych, I. Luzinov, and G. Chumanov, J. Phys. Chem. B 106, 1280 (2002).

${ }^{9}$ C. Corten, K. Kretschmer, and D. Kuckling, Beilstein J. Org. Chem. 6, 756 (2010).

${ }^{10}$ U. Borchert, U. Lipprandt, M. Bilang, A. Kimpfler, A. Rank, R. Peschka-Suss, R. Schubert, P. Lindner, and S. Forster, Langmuir 22, 5843 (2006).

${ }^{11}$ D. Cho, A. Noro, A. Takano, and Y. Matsushita, Macromolecules 38, 3033 (2005).

${ }^{12}$ F. S. Bates and G. H. Fredrickson, Phys. Today 52(2), 32 (1999).

${ }^{13}$ S. G. Jang, A. Khan, C. J. Hawker, and E. J. Kramer, Macromolecules 45, 1553 (2012).

${ }^{14}$ P. Mokarian-Tabari, R. Senthamaraikannan, C. Glynn, T. W. Collins, C. Cummins, D. Nugent, C. O'Dwyer, and M. A. Morris, Nano Lett. 17, 2973 (2017).

${ }^{15}$ C. Cummins and M. A. Morris, Microelectron. Eng. 195, 74 (2018).

${ }^{16}$ N.-G. Kang, B.-G. Kang, H.-D. Koh, M. Changez, and J.-S. Lee, React. Funct. Polym. 69, 470 (2009).

${ }^{17}$ S. Pal, "Pyridine: A useful ligand in transition metal complexes," in Pyridine, edited by P. P. Pandey (InTechOpen, London, 2018), pp. 57-74.

${ }^{18}$ U. Rafique, M. Mazhar, S. Ali, and F. A. Khwaja, Synth. Met. 78, 73 (1996).

${ }^{19}$ Z. Zhang, T. Dwyer, S. M. Sirard, and J. G. Ekerdt, J. Vac. Sci. Technol. A 37, 020905 (2019).

${ }^{20}$ D. Berman, S. Guha, B. Lee, J. W. Elam, S. B. Darling, and E. V. Shevchenko, ACS Nano. 11, 2521 (2017).

${ }^{21}$ J. W. Elam et al., ECS Trans. 69, 147 (2015).

${ }^{22}$ Y.-C. Tseng, Q. Peng, L. E. Ocola, D. A. Czaplewski, J. W. Elam, and S. B. Darling, J. Mater. Chem. 21, 11722 (2011).

${ }^{23}$ J.-P. Rueff et al., J. Synchrotron Radiat. 22, 175 (2015).

${ }^{24}$ A. Herrera-Gomez, F. S. Aguirre-Tostado, P. G. Mani-Gonzalez, M. Vazquez-Lepe, A. Sanchez-Martinez, O. Ceballos-Sanchez, R. M. Wallace, G. Conti, and Y. Uritsky, J. Electron Spectrosc. Relat. Phenomena 184, 487 (2011).

${ }^{25}$ T. Sierański, J. Mol. Model. 23 (2017).

${ }^{26} \mathrm{M}$. Snelgrove et al., "Hard x-ray photoelectron spectroscopy study of copper formation by metal salt inclusion in a polymer film," J. Phys. D. Appl. Phys. (unpublished).
${ }^{27}$ P. Papadopoulos, D. Peristeraki, G. Floudas, G. Koutalas, and N. Hadjichristidis, Macromolecules 37, 8116 (2004).

${ }^{28} \mathrm{R}$. Lundy et al., "Selective area deposition infiltration strategies and mechanisms in block copolymer and polymer brush films," ACS Omega (unpublished).

${ }^{29}$ J. J. Lebrun and H. Porte, "Polysiloxanes," in Comprehensive Polymer Science and Supplements, edited by G. Allen and J. C. Bevington (Pergamon, New York, 1989), pp. 593-609.

${ }^{30}$ C. J. Brinker, J. Non Cryst. Solids 100, 31 (1988).

${ }^{31}$ A. Herrera-Gomez, M. Bravo-Sanchez, O. Ceballos-Sanchez, and M. O. Vazquez-Lepe, Surf. Interface Anal. 46, 897 (2014).

${ }^{32} \mathrm{~J}$. Muñoz-Flores and A. Herrera-Gomez, J. Electron Spectrosc. Relat. Phenomena 184, 533 (2012).

${ }^{33}$ A. Herrera-Gomez, Internal Report (2008), available at http://www.qro. cinvestav.mx/ aherrera/reportesInternos/arxpsAnalysisSharpIntefaces.pdf.

${ }^{34}$ O. Ceballos-Sanchez, A. Sanchez-Martinez, M. O. Vazquez-Lepe, T. Duong, R. Arroyave, F. Espinosa-Magana, and A. Herrera-Gomez, J. Appl. Phys. 112, 053527 (2012).

${ }^{35}$ A. Herrera-Gomez, Y. Sun, F.-S. Aguirre-Tostado, C. Hwang, P.-G. Mani-Gonzalez, E. Flint, F. Espinosa-Magaña, and R. M. Wallace, Anal. Sci. 26, 267 (2010).

${ }^{36}$ T. Susi, T. Pichler, and P. Ayala, Beilstein J. Nanotech. 6, 177 (2015).

${ }^{37}$ Y. Liu et al., Adv. Funct. Mater. 21, 986 (2011).

${ }^{38}$ A. Mohtasebi, T. Chowdhury, L. H. H. Hsu, M. C. Biesinger, and P. Kruse, J. Phys. Chem. C 120, 29248 (2016).

${ }^{39}$ M. T. Greiner, M. Festin, and P. Kruse, J. Phys. Chem. C 112, 18991 (2008).

${ }^{40} \mathrm{G}$. Beamson and D. Briggs, J. Electron Spectrosc. 62, 220 (1993).

${ }^{41}$ G. Gabka, P. Bujak, K. Giedyk, K. Kotwica, A. Ostrowski, K. Malinowska, W. Lisowski, J. W. Sobczak, and A. Pron, Phys. Chem. Chem. Phys. 16, 23082 (2014).

${ }^{42}$ M. Barber, J. A. Connor, M. F. Guest, I. H. Hillier, and M. Schwarz, J. Chem. Soc. Faraday Trans. 2 69, 551 (1973).

${ }^{43}$ G. Calderón-Ayala et al., Carbon Lett. 21, 93 (2017).

${ }^{44}$ H.-W. Tien, Y.-L. Huang, S.-Y. Yang, J.-Y. Wang, and C.-C. M. Ma, Carbon 49, 1550 (2011).

${ }^{45}$ A. Herrera-Gomez, F. S. Aguirre-Tostado, Y. Sun, R. Contreras-Guerrero, R. M. Wallace, Y. Hisao, and E. Flint, Surf. Interface Anal. 39, 904 (2007).

${ }^{46}$ S.-W. Kuo, C.-H. Wu, and F.-C. Chang, Macromolecules 37, 192 (2004).

${ }^{47}$ S. U. D. Khan, B. Ahmed, S. K. Raghuvanshi, and M. A. Wahab, Indian J. Pure Appl. Phys. 52, 192 (2014), available at http://op.niscair.res.in/ index.php/IJPAP/article/view/1767/285.

${ }^{48}$ L. C. Cesteros, J. R. Isasi, and I. Katime, Macromolecules 26, 7256 (1993).

${ }^{49}$ A. Grill, Annu. Rev. Mater. Res. 39, 49 (2009). 